\title{
Rapid Screening of Lectins for Multivalency Effects with a Glycodendrimer Microarray
}

\author{
Núria Parera Pera, ${ }_{1}^{[a]}$ Hilbert M. Branderhorst, ${ }_{t}^{[a]}$ Raymond Kooij, $_{1}^{[a]}$ Caroline Maierhofer, ${ }^{[b]}$ \\ Marjolein van der Kaaden, ${ }^{[\mathrm{a}]}$ Rob M. J. Liskamp, ${ }^{\left[{ }^{[a]}\right.}$ Valentin Wittmann, ${ }^{[\mathrm{b}]}$ Rob Ruijtenbeek, $^{[\mathrm{c}]}$ \\ and Roland J. Pieters*[a]
}

Multivalency is an important phenomenon in protein-carbohydrate interactions. In order to evaluate glycodendrimers as multivalent inhibitors of carbohydrate binding proteins, we displayed them on a microarray surface. Valencies were varied from 1 to 8 , and corrections were made for the valencies so that all surfaces contained the same amount of the sugar ligand. Five different carbohydrates were attached to the den- drimers. A series of fluorescent lectins was evaluated, and for each of them a binding profile was obtained from a single experiment showing both the specificity of the lectin for a certain sugar and whether it prefers multivalent ligands or not. Very distinct binding patterns were seen for the various lectins. The results were rationalized with respect to the interbinding distances of the lectins.

\section{Introduction}

Protein-carbohydrate interactions control important biological processes and are often multivalent in nature. ${ }^{[1]}$ Making strategic use of protein-carbohydrate interactions or interfering with them can potentially lead to therapeutics ${ }^{[2]}$ to treat inflammation, ${ }^{[3]}$ bacterial toxins, ${ }^{[4]}$ bacterial infections, ${ }^{[5]}$ cancer, $^{\left[{ }^{[6]}\right.}$ flu $^{[7]}$ and AIDS. ${ }^{[8]}$ Because multivalency is an important aspect that can increase the potency of the relatively weak protein-carbohydrate interaction to biologically relevant levels, a natural strategy of interference is to produce multivalent inhibitors. Many cases of potent multivalency effects have been reported that involve multivalent carbohydrates. To obtain enhanced potencies, many activities have centered on glycodendrimers $^{\left[{ }^{1 b]}\right.}$ but also polymers, and nanoparticles were used ${ }_{1}^{\left[{ }^{[\mathrm{c}]}\right]}$ and combinatorial approaches have also been described. ${ }^{[9]}$ When strong effects are observed with carbohydrates of relatively low valency, chelation is the likely cause. ${ }^{[1]}$ This involves the simultaneous binding of multiple carbohydrate (sub)ligands of a multivalent carbohydrate to multiple binding sites; this benefits from reduced entropic barriers in the binding of the second and additional (sub)ligands. Very strong multivalency effects of up to factors of $10^{6}$ have been measured with bacterial toxins and other multisite lectins. ${ }^{[10,18,19]}$ Recently we took a step to study multivalency effects more efficiently by using a microarray. Microarrays are increasingly being explored in the study of protein-carbohydrate interactions. ${ }^{[11,12]}$ In order to specifically study multivalency effects, glycodendrimers were used and attached to porous aluminum oxide flowthrough microarray chips ${ }^{[13]}$ that had been used successfully for recognition studies of the other major classes of biomolecules. ${ }^{[14]}$ Although this was only done for mannose-containing dendrimers, it was shown that in a single experiment, an evaluation could be performed that provided information about the magnitude of multivalency effects for dendrimers ranging in valencies of up to eight. Interestingly, the binding could be observed in real time in much the same way as common for surface plasmon resonance detection. The porous nature of the chip material increases the surface area 500-fold in comparison with a 2D surface, thus favoring the observation of weak protein-carbohydrate interactions. The use of a 3D display of carbohydrate ligands has also been noted by others to increase the detection sensitivity. ${ }^{[15]}$ In our case, the long pores of the chip material also seemed to further enhance the binding phenomena due to the increased rebinding possibilities. ${ }^{[13]}$ Multivalency effects for concanavalin A and the GNA lectin from snowdrop with the porous aluminum oxide displayed mannosides were small and large, respectively. This correlated with their potential to allow chelation, as estimated by the inter-binding-site distance, which is only possible for GNA. The study of multivalency effects by using this method is possible because, on average, individual molecules are relatively far apart due to the large surface area. Therefore, interactions only take place between individual lectins and individual glycodendrimers. Unwanted intermolecular chelation of monovalent ligands was not observed.

\footnotetext{
[a] Dr. N. Parera Pera, Dr. H. M. Branderhorst, R. Kooij, M. van der Kaaden, Prof. Dr. R. M. J. Liskamp, Dr. R. J. Pieters Department of Medicinal Chemistry and Chemical Biology Utrecht Institute for Pharmaceutical Sciences, Utrecht University P.O. Box 80082, 3508TB Utrecht (The Netherlands) Fax: $(+31) 30-2536944$

[b] Dr. C. Maierhofer, Prof. Dr. V. Wittmann Universität Konstanz, Fachbereich Chemie Fach 709, 78457 Konstanz (Germany)

[c] Dr. R. Ruijtenbeek Pamgene International B.V. P. O. Box 1335, 5200 BJ 's-Hertogenbosch (The Netherlands)
} 
We here present our data for a new multivalent carbohydrate microarray that contains five carbohydrate structures as one dimension of variation and valencies ranging from one to eight as the other dimension (Figure 1). A sizeable series of lec-

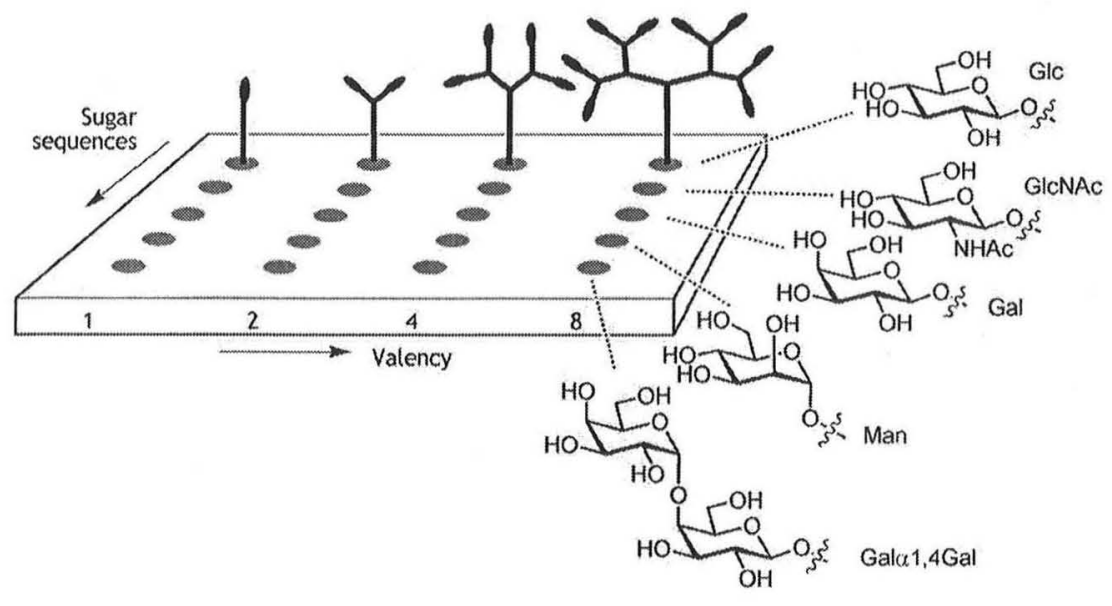

Figure 1. Schematic display of the glycodendrimer microarrays on the chip.

tins was evaluated, each with its own ligand specificity. It was found that the specificity of the lectin for monovalent ligands is maintained at higher valency. Furthermore, multivalency effects were also clearly observed in selected cases but were absent in others, thus providing additional insights into multivalent binding. Again, no indication of intermolecular chelation of monovalent ligands was observed (Supporting Information). The identification of potent ligands by the assay was validated by an inhibition assay of the tetravalent galactoside that effectively blocked the $P$. aeruginosa lectin lecA.

\section{Results and Discussion}

\section{Glycodendrimer synthesis and microarray preparation}

The glycodendrimers were synthesized according to Scheme 1. Compounds $1-4 a_{1}{ }^{[13]}$ which are alkynes ranging in valency from 1 to 8 , were conjugated to the azide-containing sugars 5-9 by CUAAC click chemistry according to our previously reported conditions. ${ }^{[16]}$ The obtained products were subsequently treated with NaOMe to liberate the protected hydroxyl groups then treated with trifluoroacetic acid (TFA) to deprotect the amine function in the core of the structures for coupling to the chip surface. As such, compounds $1-4 b-f$ (with the exception of $\mathbf{2} \mathrm{f}, \mathbf{4} \mathrm{d}$ and $\mathbf{4 f}, \mathbf{1} \mathrm{f}$ was prepared from pentynoic acid by using the same procedure) were purified by preparative HPLC and characterized by NMR spectroscopy and MS analysis. They were subsequently immobilized onto the maleimide-functionalized aluminum oxide microarray slides surface by using piezoelectric spotting of $330 \mathrm{pL}$ per spot at $\mathrm{pH}$ 9. The sugar concentration of the spotting was varied from 0.5 to $5 \mathrm{~mm}$, and as before, ${ }^{[13]}$ a correction was made for the valency.
This correction means that in the subsequent binding studies we compared spots made from, for example, a $1000 \mu \mathrm{M}$ spotting solution of monovalent $1 \mathrm{e}$ to those made from a $125 \mu \mathrm{M}$ $(1000: 8)$ spotting solution of octavalent $4 \mathrm{e}$. As such these spots contain an equal amount of sugars, because the correlation between effective immobilization and spotting solution concentration is essentially linear for the porous chip material with the very large surface area and the concentrations used (see also Supporting Information). GIcNAc dendrimers 10$13 \mathrm{~b}$ were also prepared by following a similar click chemistry route as shown in Scheme 2. These compounds cannot be attached to a microarray surface but served as inhibitors in solution by using a conventional enzyme-linked lectin assay (ELLA), to be compared to the microarray assay.

\section{Binding experiments with WGA}

The glycodendrimer microarrays were treated with various lectins outfitted with fluorescein moieties for signal generation. BSA was used for blocking the non-functionalized areas. A concentration range of FITC-labeled lectins was applied to the chips, and the fluorescent signal was periodically recorded for $2 \mathrm{~h}$, quantified and averaged for the duplicate spots, and converted to progress curves. This periodic monitoring of the binding process is possible because of the use of porous chips, which allow the analyte solution with the fluorescent protein to be pumped up and down (to avoid diffusion limitations) through the microchannels. This process occurs because of air pressure control below the chip. Pictures were taken periodically with a CCD camera when the unbound fluorescent component was temporarily below the chip and therefore out of the frame. In this way only fluorescence resulting from binding is detected. In addition to the progress curves, a histogram of end values was also made for each lectin at the lowest spotting concentration that gave an adequate signal to see the binding selectivity and multivalency effects at a glance. Of a series of nine lectins we started with wheat germ agglutinin (WGA). WGA is a dimeric protein with eight binding sites for GlcNAc that are separated by distances varying from approximately 14 to $53 \AA . .^{[17,18]}$ The picture that emerged from the binding experiment is shown in Figure $2 \mathrm{~A}$. Of the five carbohydrate sequences on the array, only the GlcNAc-presenting spots, that is, those displaying compounds $1-4 \mathrm{c}$ showed significant fluorescence. Because all the other spots remained dark, it can be concluded that the inherent GICNAc specificity is faithfully maintained for systems of higher valencies. The higher-valent ligands of the "wrong" type are not able to over- 


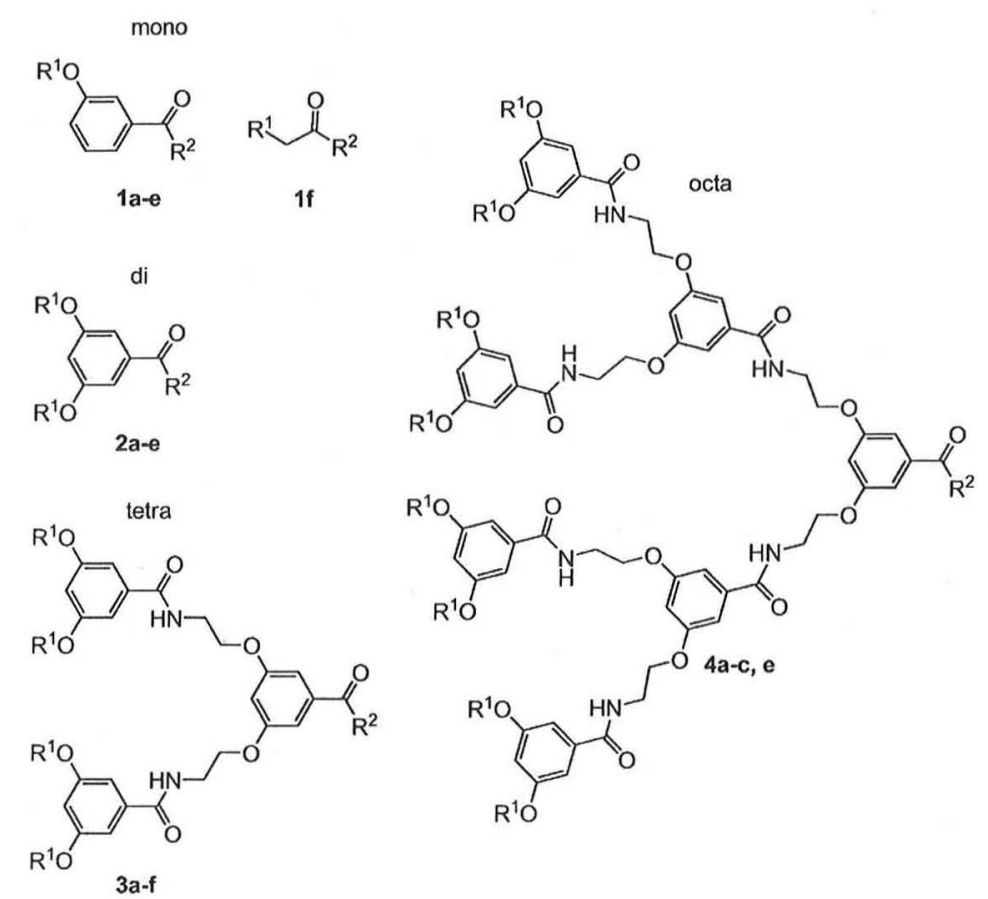

$5 \underbrace{A C O}_{O A C} O_{Y} y_{3}$

$6 \quad$

$7{ }_{\mathrm{OAC}}^{\mathrm{OCO}} \mathrm{O}_{y_{3}}^{\mathrm{OAC}}$

8

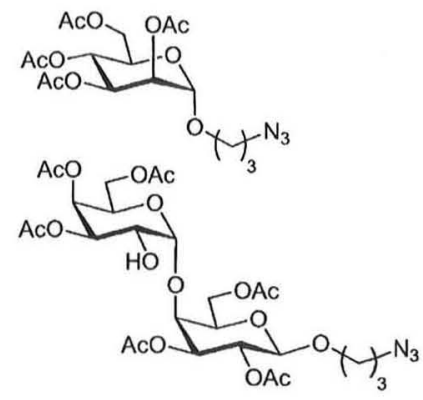

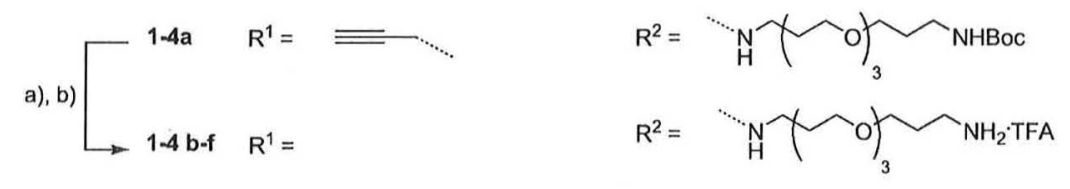
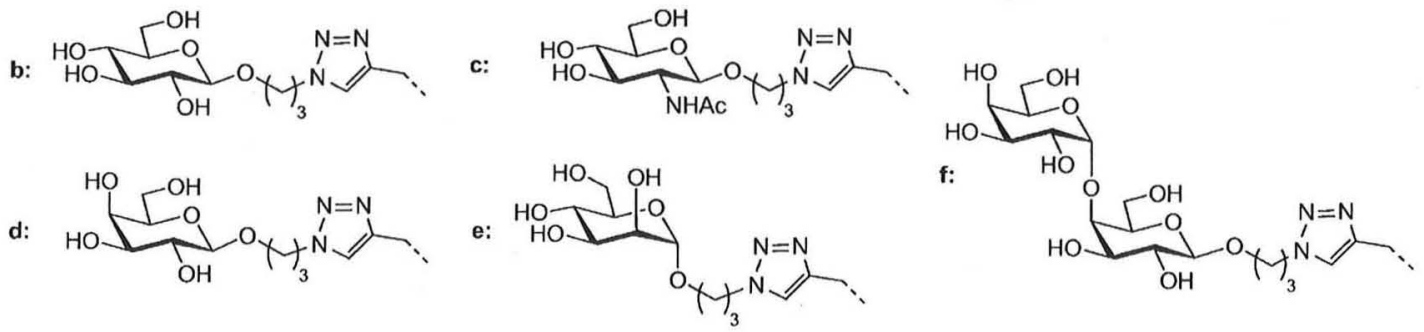

Scheme 1. Synthesis of glycodendrimers for attachment to a microarray surface. Reagents and conditions: a) $5-9, \mathrm{CuSO}_{4}$, sodium ascorbate, $\mathrm{DMF} / \mathrm{H}_{2} \mathrm{O}, 80^{\circ} \mathrm{C}$, $20 \mathrm{~min}, 65-80 \%$; b) i: $\mathrm{NaOMe}, \mathrm{MeOH}$; ii: TFA, $\mathrm{H}_{2} \mathrm{O}$, quantitative.

come their inherently weaker binding by a multivalent presentation. The outcome of the experiment is also displayed in the graph of Figure $2 \mathrm{~B}$, which directly shows the selectivity. It is also clear that the binding to the monovalent GICNAC $1 \mathrm{c}$ is very weak in comparison to the binding to the di-, tetra-, and octavalent 2-4c. The multivalency effect can also clearly be observed in the real-time monitoring of the binding of fluorescent WGA to GICNAC displaying spots of the microarray. Figure 3 shows the progress of the binding events as determined from the periodic fluorescent images. Besides the clear binding differences between the binding to the monovalent $1 \mathrm{c}$ and the others, it can also be seen that the WGA binding to the monovalent $1 \mathrm{c}$ reaches equilibrium significantly faster than the binding to compounds of higher valency.
The binding of the WGA typically seems to benefit a great deal from multivalency effects of the chelation type. ${ }^{[1,, 18]}$ On the microarray it is conceptually possible that the monovalent GlcNAc moieties of $\mathbf{1 c}$ are displayed in such a dense format that they would be brought within chelation distance (about $54 \AA$ is the longest distance between WGA binding sites ${ }^{[17,18]}$ ) and would bind through intermolecular chelation. Judging from Figure 2 and 3, this is not the case, because the binding to the monovalent $1 \mathrm{c}$ is far behind that of the higher-valent sugars 2-4c. Furthermore, the signal of binding to $1 \mathrm{c}$ versus the spotting concentration is a straight line and does not curve upward (see the Supporting Information). This can be attributed to the 500-fold larger surface area of the three-dimensional porous aluminum oxide chip material, in comparison to 

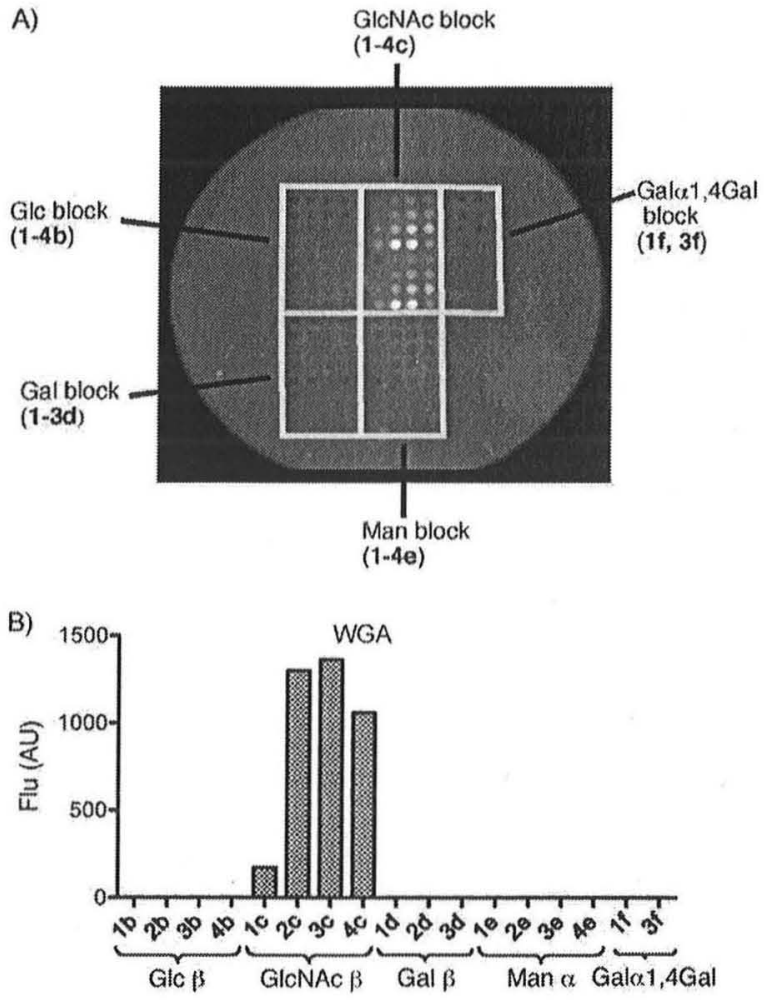

Figure 2. A) Fluorescence image of microarray incubated with fluorescent WGA lectin. B) Measured fluorescence for each of the compounds displayed on the microarray. [WGA] $2 \mu \mathrm{g} \mathrm{mL}^{-1}$, spotting concentration sugars $0.5 \mathrm{~mm}$.
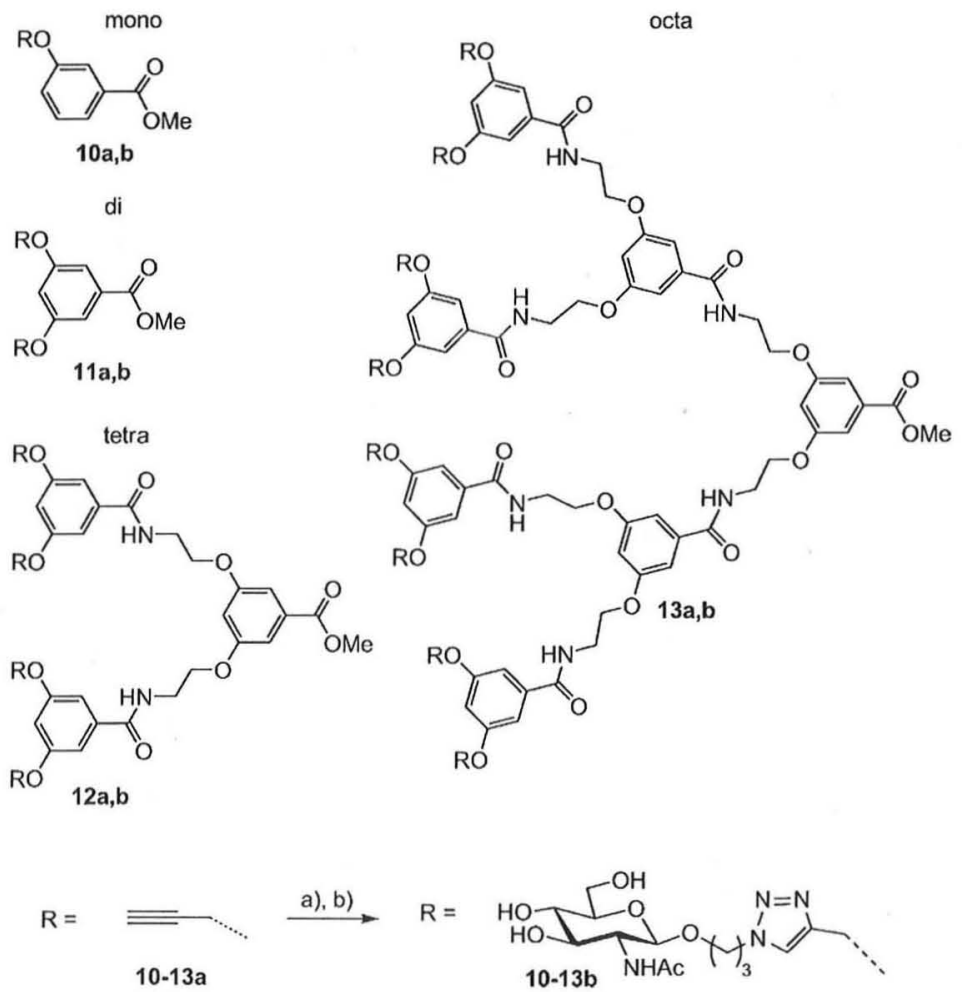

Scheme 2. Synthesis of glycodendrimers as soluble WGA inhibitors. Reagents and conditions: a) 6, $\mathrm{CuSO}_{4}$, sodium ascorbate, DMF, $80^{\circ} \mathrm{C}, 20 \mathrm{~min}$, b) $\mathrm{NaOMe}, \mathrm{MeOH},(32-69 \%$, two steps).

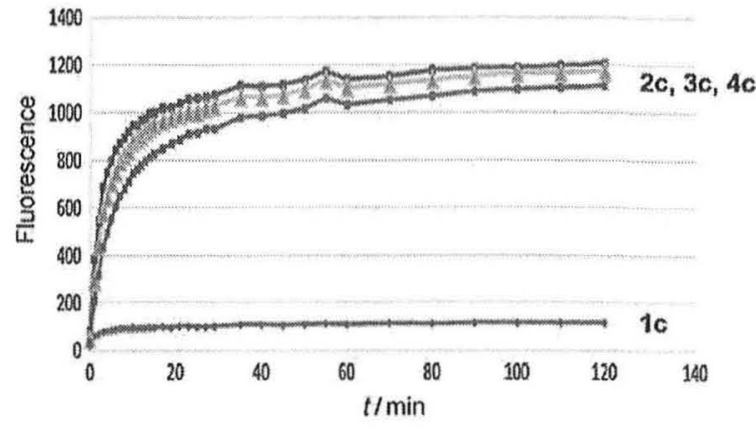

Figure 3. Real-time monitoring of the binding of WGA $\left(2 \mu \mathrm{g} \mathrm{mL}^{-1}\right)$ to the GlcNAc displaying spots 1-4c.

a two dimensional surface. This places the individual compounds far from each other and is also substantiated by a calculation (Supporting Information).

To validate the results with WGA, a more conventional assay (ELLA) was used to compare the microarray data. To this end, inhibition of horseradish-peroxidase (HRP)-labeled WGA binding to an immobilized GIcNAc ligand was determined as previously described. ${ }^{[19]}$ The results are shown in Table 1. The free sugar GICNAc inhibited the WGA binding with an $\mathrm{IC}_{50}$ of $30 \mathrm{~mm}$. The conjugated monovalent inhibitor $10 \mathrm{~b}$ improved the inhibitory potency by a factor of 10 . However, a major jump was observed in the inhibitory potency of the divalent $\mathbf{1 1} \mathrm{b}$, which increased by a factor of 42 ( 21 per sugar residue) in comparison with $10 \mathrm{~b}$. Further increase of the valency led to additional potency increases with the $\mathrm{IC}_{50}$ of the tetravalent $12 \mathrm{~b}$ being in the same range as a previously reported tetravalent GICNAC derivative tested in the same assay ${ }^{[19]}$ and also in a hemagglutination assay ${ }^{[20]}$ and an SPR assay. ${ }^{[15 c]}$ The octavalent $\mathbf{1 3} \mathrm{b}$ was even more potent; in fact, conjugation and multivalent presentation taken together led to a potency increase over GICNAc of close to 5000fold. When comparing these ELLA results with the microarray images it is clear in both cases that multivalency plays an important role in the binding. In the microarray the WGA binds only weakly to monovalent $1 \mathrm{c}$ and much more strongly to the higher valent 2-4c. In the ELLA, the jump in inhibitory potency is the strongest between the monovalent $10 \mathrm{~b}$ and the

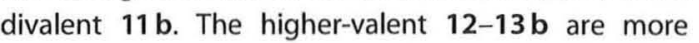
potent inhibitors than the divalent $11 \mathrm{~b}$ in the ELLA, a result that is not mirrored in the microarray images. The assays are actually significantly different for example, with respect to mobility of the ligands. It is possible that aggregation plays an additional beneficial role above the chelation in the ELLA, a phenomenon that we previously observed for cholera toxin inhibition. ${ }^{[21]}$ Nevertheless the microarray provided a rapid evaluation to identify both the ligand specificity and the multivalency effects in the lectin binding. As mentioned, considering the short interbinding site distance of about $14 \AA$ in $\mathrm{WGA}_{1}{ }^{[17,18]}$ the chelation 
Table 1. Inhibition of binding of HRP-labeled WGA ${ }^{(a)}$ to a covalently immobilized GICNAC derivative (ELLA) by compounds 10-13 b.

\begin{tabular}{|lccc|}
\hline Compound & $\begin{array}{l}\text { Ligand } \\
\text { valency }\end{array}$ & $\begin{array}{l}\mathrm{IC}_{50} \\
{[\mu \mathrm{M}]}\end{array}$ & $\begin{array}{l}\text { Relative potency } \\
\text { (per sugar) }\end{array}$ \\
\hline GlcNAc & 1 & 30000 & $1(1)$ \\
$10 \mathrm{~b}$ & 1 & 3000 & $10(10)$ \\
$11 \mathrm{~b}$ & 2 & 72 & $417(208)$ \\
$12 \mathrm{~b}$ & 4 & 9 & $3333(833)$ \\
$13 \mathrm{~b}$ & 8 & 0.8 & $37500(4688)$ \\
\hline [a] [WGA-HRP]: $1 \mu \mathrm{g} \mathrm{mL}^{-1}$. & & \\
\hline
\end{tabular}

mechanism seems likely for the binding of WGA to the type of glycodendrimers used here.

\section{Binding experiments with a series of lectins}

Experiments were continued with the following lectins: concanavalin A (ConA) ${ }^{[22]}$ Griffonia simplicifolia $(\mathrm{GS}-1)^{[23]}$ cholera toxin $(\mathrm{CT})^{[24]}$ Datura stramonium (DSA), ${ }^{[25]}$ Lens culinaris (LCA), ${ }^{[26]}$ Pseudomonas aeruginosa (PA-IL or LecA), ${ }^{[27]}$ Pisum sativum (PSA), ${ }^{[28]}$ and the peanut agglutinin (PNA). ${ }^{[29]}$ The end values of the array experiments are displayed in Figure 4 for each of the lectins. Notable selectivity patterns can be observed. In each case several protein concentrations were tested in order to find the lowest concentration that still provided a reasonable signal.

The results for concanavalin A (Figure 4A), show an absolute preference for the $\alpha$-linked mannosides 1 $4 \mathrm{e}$. Within the series of $\alpha$-linked mannose compounds a moderate preference for the higher-valent systems is observed. ConA is a tetrameric plant lectin from the jack bean with a binding specificity for $\alpha$ linked mannosides and glucosides. The protein is a tetramer at neutral $\mathrm{pH}$ with four subunits in a tetrahedral orientation, which leads to a separation between the binding sites of about $72 \AA$ (PDB ID: $\left.1 \mathrm{VAM}^{(30)}\right)$; this is too long to be effectively spanned by the dendrimers on the chip and explains the moderate multivalency effect. The picture is very similar to that obtained with our previous microarray that only contained mannosides. ${ }^{[13]}$ Furthermore, the relative intensities of the different valencies is the same with FITC-labeled ConA of different commercial sources, further supporting the reproducibility of the experiments.

GS-1 is a lectin isolated from the seeds of the African leguminous shrub Griffonia simplicifolia. ${ }^{[23]}$ The lectin consists of a mixture of five tetrameric isolectins that vary in their content of $A$ and $B$ subunits. The $A$ subunit was found to bind strongly to both $\alpha$ linked GalNAc and Gal residues while the B subunit has a strong preference for $\alpha$-linked Gal. As shown in Figure $4 \mathrm{~B}$, the strongest binding was observed to the galabiose dendrimers displaying Gala1,4Gal, which gave stronger binding than the $\beta$-galactose dendrimers, in accordance to the known preference for $\alpha$-linked Gal. There was no major preference for the tetravalent galabioside $\mathbf{3} \mathrm{f}$ over the monovalent $\mathbf{1} \mathrm{f}$. The crystal structure of the $B_{4}$ tetramer shows that the shortest interbinding site distance is about $51 \AA$ (PDB ID: $1 \mathrm{HQL}^{[23 \mathrm{c}]}$ ), which is too long for effective chelation.

The results for the lectin from lentils, Lens culinaris (LCA) ${ }^{[26]}$ are shown in Figure 4C. LCA is a homodimeric lectin in which each monomer consists of an $\alpha$ and a $\beta$ chain. Its reported specificity is for $\alpha$-linked Glc and Man. In accordance, only binding to the $\alpha$-linked Man derivatives 1-4 e was observed. In this case the multivalency effect observed is rather small, because the distance between the binding sites is around $70 \AA$ (X-ray structure 1 LES ${ }^{[26 c]}$ ) and too large to allow chelation.

PSA, the lectin of Pisum sativum (pea), is a very similar lectin to $\mathrm{LCA}^{\left[{ }^{[28]}\right.}$ The binding profile of the chip is also very similar (Figure 4D). Only binding to $\alpha$-linked Man derivatives $1-4 \mathrm{e}$ was observed and with little multivalency effect. The latter observation is in agreement with the long distance between the binding sites of about $68 \AA$ (X-ray structure $\left.1 \mathrm{BQP}^{[28 \mathrm{~b}]}\right)$.
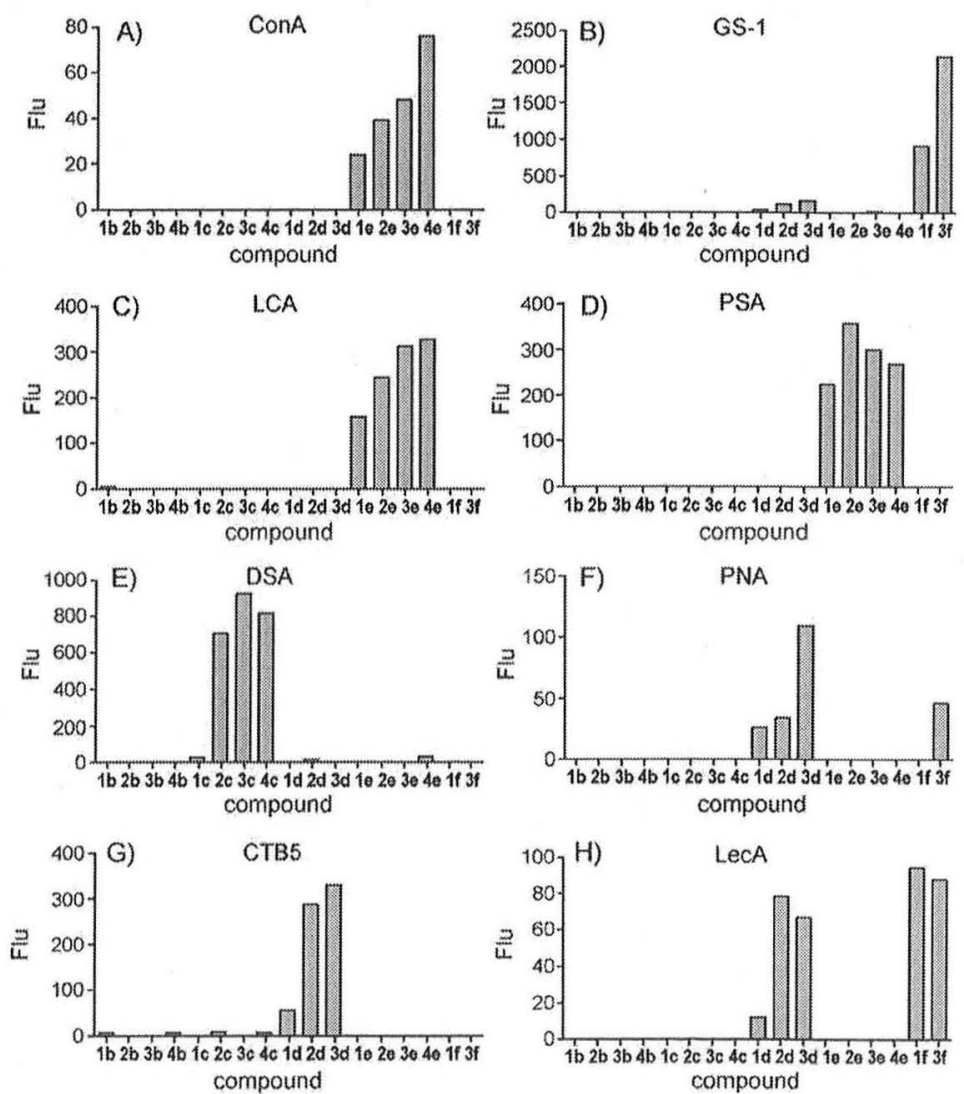

Figure 4. Degree of binding of a series of eight lectins to the glycodendrimer microarray. A) [ConA] $10 \mu \mathrm{g} \mathrm{mL}^{-1}$, spotting conc. sugars $2.5 \mathrm{~mm}$; B) [GS-1] $25 \mu \mathrm{g} \mathrm{mL}^{-1}$, spotting conc. sugars $5 \mathrm{~mm}$; C) [LCA] $10 \mu \mathrm{g} \mathrm{mL}^{-1}$, spotting conc. sugars $2.5 \mathrm{~mm}$; D) [PSA] $5 \mu \mathrm{g} \mathrm{mL}^{-1}$. spotting conc. sugars $2.5 \mathrm{~mm}$; E) [DSA] $1.5 \mu \mathrm{g} \mathrm{mL}^{-1}$ spotting conc. sugars $2.5 \mathrm{~mm}$; F) [PNA] $5 \mu \mathrm{g} \mathrm{mL}^{-1}$, spotting conc. sugars $5 \mathrm{~mm}$; G) [CTB5] $60 \mu \mathrm{g} \mathrm{mL}^{-1}$, spotting conc. sugars $5 \mathrm{~mm}$; H) [LecA] $10 \mu \mathrm{g} \mathrm{mL}^{-1}$, spotting conc. sugars $0.5 \mathrm{~mm}$. 
The seeds of Datura stramonium (jimson weed or thorn apple) contain the $\beta$-GIcNAc-specific DSA lectin. ${ }^{[25]}$ The lectin was shown to only bind to the $\beta$-linked GICNAc derivatives 1$4 c$ (Figure 4E). Furthermore, whereas strong binding was seen for the di- to octavalent $2-4 c$, the lectin binds very weakly to monovalent $1 c$; this suggests that lectin binding greatly benefits from chelation. Although no crystal structure of the lectin is available, solution inhibition data confirm the preference of at least a divalent saccharide. A divalent sugar was shown to bind 240-fold more strongly than its monovalent counterpart. ${ }^{[25 b]}$

Peanut agglutinin (PNA) ${ }^{[29]}$ is a galactose-specific tetrameric lectin with identical subunits and an asymmetric structure. The interbinding site distances are between 54 and $74 \AA$, based on a crystal structure $\left(1 \mathrm{QF} 3^{[29]}\right)$. The lectin showed the strongest binding to the $\beta$-linked Gal compounds $1-3 d$, for which a modest multivalency effect was noted (Figure 4F). Binding to the Gal $1,4 \mathrm{Gal}-$ containing compound $4 \mathrm{f}$ was also observed but not to the monovalent $\mathbf{1} \mathrm{f}$; this might indicate a larger multivalency effect. Generally multivalency effects with small multivalent sugars binding to PNA have been small, ${ }^{[3]}$ but in selected cases, effects of around one order of magnitude have been reported. ${ }^{[32]}$

Cholera toxin $(C T)^{[24]}$ is a member of the $A B_{5}$ toxins that contain a disease-causing $A$-subunit surrounded by five carbohydrate-binding B-subunits. These B-subunits attach the toxins to cell surfaces as a first step towards disease. Although the natural target ligand is GM1, binding to the terminal $\beta$-linked Gal by the B-subunit $\left(\mathrm{CTB}_{5}\right)$ is well-known. ${ }^{[33]}$ Figure $4 \mathrm{G}$ shows that only binding to the $\beta$-linked Gal was observed. Furthermore, a preference for the di- and tetravalent $2,3 \mathrm{~d}$ and considerably weaker binding to the monovalent $1 \mathbf{d}$ was observed. Whereas large multivalency effects to dendrimers of this type have previously been shown, ${ }^{[10 c, 34]}$ longer spacer arms are likely needed for optimal multivalency effects, ${ }^{[35]}$ This is due to the relatively large distance between the binding sites of about $30 \AA$ (crystal structure $3 \mathrm{CHB}^{[24 b]}$ ).

Finally, PA-IL or LecA is a galactose-binding tetrameric protein from Pseudomonas aeruginosa that is associated with virulence. ${ }^{[27]}$ The closest distance between two of its binding sites is $26 \AA$ (X-ray structure $10 K O$ ). ${ }^{[36]}$ Figure $4 \mathrm{H}$ shows that the lectin binds both to $\beta$-linked $\mathrm{Gal}$ and the Gal $\alpha 1,4 \mathrm{Gal}$ linked compounds. Strong binding was observed to the galabiose compounds, which were previously noted to be strong monovalent ligands. ${ }^{[37]}$ Strikingly in the galactose case, strong binding was only detected to the di- and tetravalent conjugates but not to the monovalent. This is in agreement with the interbinding site distance of this lectin. A sensitivity of this lectin to the display of multivalent carbohydrates was recently noted, ${ }^{[38]}$ but otherwise our microarray result provides valuable input for further inhibitor design of this medically important lectin, which is a key virulence factor of Pseudomonas aeruginosa. ${ }^{[39]}$ To validate the discovery that the tetravalent galactoside is a potent inhibitor, an inhibition assay was performed. To this end the LecA protein was applied to the chip in various wells in the presence of a concentration range of the tetravalent $\mathbf{3 d}$ and the monovalent $\mathbf{1} \mathrm{d}$ in solution. The obtained $I C_{50}$ value for the tetravalent $3 \mathrm{~d}$ was $2.6 \mu \mathrm{M}$ and for the monovalent $1 \mathrm{~d}$ this number was $163 \mu \mathrm{M}$, that is, that tetravalent was 63 -fold more potent (or 16 -fold per sugar). This indicates that the on-chip screening correctly identifies the potent multivalent inhibitor and is another indication, along with the mentioned WGA inhibition assay, that the results translate well to the solutionphase inhibitory properties.

\section{Conclusions}

A microarray of glycodendrimers was constructed and evaluated for binding to a series of lectins. These lectins all contained multiple carbohydrate binding sites spaced at different distances. The results showed that WGA, a lectin containing at least two closely spaced binding sites, showed a strong multivalency effect on the chip, a result that correlated well with inhibition results of ELLA experiments in which the related glycodendrimers were used as inhibitors, that is, in solution. Besides the multivalency effect, it was also clear that the carbohydrate specificity was maintained at high valency. Binding was only seen to the GlcNAc-displaying compounds and not to the other monosaccharides, even at high valency. This observation extended to all the members of a series of eight additional lectins that were evaluated on the microarray. In all cases only binding was seen that was in line with the known lectin specificity; this is an encouraging observation for the design and application of multivalent carbohydrate ligands. Multivalency effects were observed in a few cases that correlated to the known inter-binding-site distances (smaller than about $30 \AA$, LecA, $\mathrm{CTB}_{5}$, WGA) or with previous experimental results (DSA). Only moderate effects were seen in cases in which inter-binding-site distances were large (i.e., larger than about $50 \AA$ ). These observations are in line with those obtained with conventional assays for all kinds of carbohydrate-binding proteins. ${ }^{[1]]}$ Statistical rebinding effects of systems in which chelation is not possible tend to be much smaller for systems of this size, with a relatively small number of attached ligands, $\left.{ }^{[1]}\right]$ than for those derived from chelation. In this assay method those effects are clearly smaller, though not completely absent, as can be seen in the case of ConA and LCA.

Lectins are also increasingly used as reagents to identify the presence of glycoproteins as, for example, biomarkers. ${ }^{[40]}$ For such studies, it is important to know the preferences of the lectins, not only for their carbohydrate sequence but also for the valencies before drawing conclusions. As a lack of signal could mean the presence of a monovalent carbohydrate while the lectin strongly prefers a biantennary version.

Real-time evaluation of a multivalent carbohydrate chip as described here is a useful, rapid, and selective screening method to evaluate multivalency effects in a single experiment. This study will be extended in the direction of other more medically interesting carbohydrate-binding proteins. The arrays can be screened with a range of lectins in parallel in a single experiment, in a short time, and with very small analyte (lectin) consumption. Furthermore, by using judiciously chosen protecting-group chemistry on the dendrimers, heteroglycoclusters could also be made to gain further information 
about the heterocluster effect. ${ }^{[41]}$ Given the expanded carbohydrate repertoires currently available, these microarrays have the potential to facilitate and accelerate various aspects of glycomics and proteomics and particularly further identify the beneficial role of multivalency in inhibitor design.

\section{Experimental Section}

General: Unless stated otherwise, chemicals were obtained from commercial sources and were used without further purification. Solvents were purchased from Biosolve (Valkenswaard, The Netherlands). Microwave reactions were carried out in a Biotage microwave Initiator (Uppsala, Sweden). The microwave power was limited by temperature control once the desired temperature was reached. A sealed vessel of $2-5 \mathrm{~mL}$ was used. Analytical HPLC runs were performed on a Shimadzu automated HPLC system with a reversed-phase column (Alltech, Adsorbosphere C $8,90 \mathrm{M}, 5 \mathrm{~mm}, 250$ L4.6 mm, Deerfield, IL, USA) that was equipped with an evaporative light-scattering detector (PLELS 1000, Polymer Laboratories, Amherst, MA, USA) and a UV/Vis detector operating at 220 and $254 \mathrm{~nm}$. Preparative HPLC runs were performed on an Applied Biosystems workstation. Elution was effected by using a linear gradient of $5 \% \mathrm{MeCN} / 0.1 \%$ TFA in $\mathrm{H}_{2} \mathrm{O}$ to $5 \% \mathrm{H}_{2} \mathrm{O} / 0.1 \%$ TFA in MeCN or by a gradient of $5 \% \mathrm{MeOH} / 0.1 \%$ TFA in $\mathrm{H}_{2} \mathrm{O}$ to $5 \% \mathrm{H}_{2} \mathrm{O} / 0.1 \%$ TFA in $\mathrm{MeOH}$. ' $\mathrm{H}$ NMR $(300 \mathrm{MHz})$ and ${ }^{13} \mathrm{C}$ NMR $(75.5 \mathrm{MHz})$ were performed on a Varian G-300 spectrometer. HSQC NMR $(500 \mathrm{MHz})$ were performed with a VARIAN INOVA-500 spectrometer. Electrospray Mass experiments were performed in a Shimadzu LCMS QP8000. MALDI-TOF experiments were run in MALDI-TOF Kratos Shimadzu Axima-CFR by using $\alpha$-Cyano-4-hydroxycinnamic acid for calibration. The FITC-labeled lectins WGA, ConA, LCA, PSA, and PNA were obtained from Sigma-Aldrich, and the lectin DSA was obtained from E.Y. Laboratories, Inc. (San Mateo, CA, USA). The toxin $\mathrm{CTB}_{5}$ was obtained from Sigma-Aldrich and the lectins LecA and GS-1 (obtained from Sigma-Aldrich) were FITC labeled according to the procedure of Sigma-Aldrich. ${ }^{[42]}$

General click chemistry conditions: Alkyne dendrimer, sugar azide ( 1.5 equiv per alkyne), $\mathrm{CuSO}_{4}$ ( 0.15 equiv/alkyne) and sodium ascorbate ( 0.3 equiv/alkyne) were dissolved in an appropriate volume of $1 \% \mathrm{H}_{2} \mathrm{O}$ in DMF. The mixture was heated under microwave irradiation to $80^{\circ} \mathrm{C}$ for $20 \mathrm{~min}$. The mixture was concentrated in vacuo, and the product was isolated by silica gel chromatography.

Microarray preparation and analysis: Dendrimer solutions with varying concentrations and valencies were printed onto the microarray slides by using piezoelectric spotting of $330 \mathrm{pL}$ per spot. A concentration range was applied from 0.1 to $5 \mathrm{~mm}$ in terms of the carbohydrates, corrected for the valency of the dendrimers in a spotting buffer of $\mathrm{pH}$ 9.0. Each array slide contained spots in duplicate. Microarray experiments were performed by using PamChip arrays run on a PamStation12 instrument (Pam-Gene B.V., 's Hertogenbosch, The Netherlands). Temperature-controlled carbohydrate glycodendrimer chips were run in parallel by pumping the sample up and down through the 3D porous chip. Data were obtained by real-time imaging of the fluorescence signal by a CCD camera. Images were analyzed by using BioNavigator software (Pam-Gene). The fluorescent intensities were expressed in arbitrary units and the relative intensities of the individual dendrimers were the average of the two duplicate spots. The specific conditions for the binding of the various lectins were as follows:

ConA: A concentration range of FITC-labeled ConA (20$10 \mu \mathrm{g} \mathrm{m}^{-1}$ ) in HEPES/BSA buffer was used that contained $\mathrm{Ca}^{2+}$ and $\mathrm{Mn}^{2+}(10 \mathrm{~mm}$ HEPES, $1 \mathrm{~mm} \mathrm{CaCl} 2,1 \mathrm{~mm} \mathrm{MnCl}, 100 \mathrm{~mm} \mathrm{NaCl}$, $0.1 \%$ BSA, pH 7.5).

LCA: A concentration range of FITC-labeled LCA $\left(25-5 \mu \mathrm{gL}^{-1}\right)$ in HEPES/BSA buffer was used that contained $\mathrm{Ca}^{2+}$ and $\mathrm{Mn}^{2+}(10 \mathrm{mM}$ HEPES, $1 \mathrm{~mm} \mathrm{CaCl} 2,1 \mathrm{~mm} \mathrm{MnCl}_{2}, 100 \mathrm{~mm} \mathrm{NaCl}, 0.1 \%$ BSA, pH 7.5).

PEA: A concentration range of FITC-labeled PEA $\left(40-5 \mu \mathrm{gLL}^{-1}\right)$ in HEPES/BSA buffer was used that contained $\mathrm{Ca}^{2+}$ and $\mathrm{Mn}^{2+}(10 \mathrm{mM}$ HEPES, $1 \mathrm{~mm} \mathrm{CaCl}, 1 \mathrm{~mm} \mathrm{MnCl}, 100 \mathrm{~mm} \mathrm{NaCl}, 0.1 \%$ BSA, pH 7.5) was used for binding experiments.

PNA: A concentration range of FITC-labeled PNA $\left(25-0.5 \mu \mathrm{g} \mathrm{mL}^{-1}\right)$ in HEPES/BSA buffer was used that contained $\mathrm{Ca}^{2+}$ and $\mathrm{Mn}^{2+}$ (10 mm HEPES, $1 \mathrm{~mm} \mathrm{CaCl} 2,1 \mathrm{~mm} \mathrm{MnCl}, 100 \mathrm{~mm} \mathrm{NaCl}, 0.1 \% \mathrm{BSA}$, $\mathrm{pH} 7.5)$.

WGA: A concentration range of FITC-labeled WGA (100-5 $\left.\mu \mathrm{g} \mathrm{mL}^{-1}\right)$ in HEPES/BSA buffer was used (10 mM HEPES, $100 \mathrm{~mm} \mathrm{NaCl}, 0.1 \%$ $B S A, p H$ 7.5).

LecA: A concentration range of FITC-labeled LecA $\left(40-5 \mu \mathrm{g} \mathrm{mL}^{-1}\right)$ in HEPES/BSA buffer was used (10 mM HEPES, $100 \mathrm{~mm} \mathrm{NaCl}, 0.1 \%$ $\mathrm{BSA}, \mathrm{pH} 7.5$ ).

GS-1: A concentration range of FITC-labeled GS-1 (250-10 $\left.\mu \mathrm{g} \mathrm{mL}^{-1}\right)$ in HEPES/BSA buffer was used (10 mM HEPES, $100 \mathrm{~mm} \mathrm{NaCl}, 0.1 \%$ BSA, $\mathrm{pH}$ 7.5).

$\mathrm{CTB}_{5}$ : A concentration range of FITC-labeled cholera toxin (25$0.5 \mu \mathrm{g} \mathrm{m}^{-1}$ ) in PBS buffer was used $(8 \mathrm{~g}$ of $\mathrm{NaCl}, 0.2 \mathrm{~g}$ of $\mathrm{KCl}$, $1.44 \mathrm{~g}$ of $\mathrm{Na}_{2} \mathrm{HPO}_{4} \cdot 12 \mathrm{H}_{2} \mathrm{O}$ and $0.24 \mathrm{~g}$ of $\mathrm{KH}_{2} \mathrm{PO}_{4}$ were dissolved in $1 \mathrm{~L} \mathrm{H}_{2} \mathrm{O}, \mathrm{pH}$ 7.4).

DSA: A concentration range of FITC-labeled DSA $\left(4-0.5 \mu \mathrm{g} \mathrm{mL}^{-1}\right)$ in PBS buffer was used $(8 \mathrm{~g}$ of $\mathrm{NaCl}, 0.2 \mathrm{~g}$ of $\mathrm{KCl}, 1.44 \mathrm{~g}$ of $\mathrm{Na}_{2} \mathrm{HPO}_{4} \cdot 12 \mathrm{H}_{2} \mathrm{O}$ and $0.24 \mathrm{~g}$ of $\mathrm{KH}_{2} \mathrm{PO}_{4}$ were dissolved in $1 \mathrm{~L} \mathrm{H}_{2} \mathrm{O}$, $\mathrm{pH}$ 7.4).

LecA inhibition assay: Aliquots of a solution of FITC-labeled LecA $\left(10 \mu \mathrm{g} \mathrm{mL}^{-1}\right)$ in HEPES/BSA buffer $(10 \mathrm{~mm}$ HEPES, $100 \mathrm{~mm} \mathrm{NaCl}$, $0.1 \% \mathrm{BSA}, \mathrm{pH} 7.5$ ), containing different concentrations of the inhibitors $1 \mathrm{~d}$ and $\mathbf{3} \mathrm{d}$ at different concentrations were incubated for $1 \mathrm{~h}$ at $4{ }^{\circ} \mathrm{C}$. and subsequently added to the glycodendrimer chip. The binding process was monitored for $2 \mathrm{~h}$ and the end values of the fluorescence detection were taken for the determination of the $I C_{50}$ by using Prism 5 (Graphpad Software, Inc.). $I C_{50}$ values were determined for the binding of LecA to the galactose containing $\mathbf{1 d}, \mathbf{2} \mathrm{d}$, and $\mathbf{3} \mathbf{d}$ and results were averaged.

\section{Acknowledgements}

This research is supported by the Dutch Technology Foundation STW, applied science division of NWO and the Technology Program of the Ministry of Economic Affairs, the Deutsche Forschungsgemeinschaft (FOR 434), and the Konstanz Research School Chemical Biology. We thank Pam-Gene B.V. ('s Hertogenbosch, The Netherlands) for immobilizing the glycodendrimers on the chip by piezoelectric spotting.

Keywords: carbohydrates · click chemistry · dendrimers inhibitors - microarrays

[1] a) J. J. Lundquist, E. J. Toone, Chem. Rev. 2002, 102, 555-578; b) R. Roy, Trends Glycosci. Glycotechnol. 2003, 15, 291-310; c) R. J. Pieters, Org. 
Biomol. Chem. 2009, 7, 2013-2025; d) R. T. Lee, Y. C. Lee, Glycoconjugate J. 2000, 17, 543-551; e) N. Jayaraman, Chem. Soc. Rev. 2009, 38, $3463-$ 3483; f) T. K. Dam, T. A. Gerken, C. F. Brewer, Biochemistry 2009, 48 3822-3827; g) J. E. Gestwicki, C. W. Cairo, L. E. Strong, K. A. Oetjen, L. L. Kiessling, J. Am. Chem. Soc. 2002, 124, 14922-14933.

[2] P. Stallforth, B. Lepenies, A. Adibekian, P. H. Seeberger, J. Med. Chem. 2009, 52, 5561-5577.

[3] C. Kneuer, C. Ehrhardt, M. W. Radomski, U. Bakowsky, Drug Discovery Today 2006, 11, 1034-1040

[4] E. Fan, E. A. Merritt, C. L. M. J. Verlinde, W. G. J. Hol, Curr. Opin. Struct. Biol. 2000, 10, 680-686.

[5] a) A. Imberty, A. Varrot, Curr. Opin. Struct. Biol. 2008, 18, 567-576 b) R. J. Pieters, Med. Res. Rev. 2007, 27, 796-816.

[6] a) S. Califice, V. Castronovo, F. Van Den Brüle, Int. J. Oncol. 2004, 25 , 983-992; b) G. Ragupathi, F. Koide, P. O. Livingston, Y. S. Cho, A. Endo, Q. Wan, M. K. Spassova, S. J. Keding, J. Allen, O. Ouerfelli, R. M. Wilson, S. J. Danishefsky, J. Am. Chem. Soc. 2006, 128, 2715-2725; C) Y. Li, P. J. Cozzi, Curr. Cancer Drug Targets 2007, 7, 259-271.

[7] a) J. Stevens, O. Blixt, T. M. Tumpey, J. K. Taubenberger, J.C. Paulson, I. A. Wilson, Science 2006, 312, 404-410; b) M. J. Kiefel, M. von Itzstein Chem. Rev. 2002, 102, 471-490.

[8] L.-X. Wang, Curr. Opin. Drug Discov. Devel. 2006, 9, 194-206.

[9] a) V. Wittmann, S. Seeberger, Angew. Chem. 2004, 116, 918-921; Angew. Chem. Int. Ed. 2004, 43, 900-903; b) E. Kolomiets, E. M. V. Johansson, O. Renaudet, T. Darbre, J. L. Reymond, Org. Lett. 2007, 9, 1465-1468.

[10] a) P. I. Kitov, J. M. Sadowska, G. Mulvey, G. D. Arnstrong, H. Ling, N. S. Pannu, R. J. Read, D. R. Bundle, Nature 2000, 403, 669-672; b) E. Fan, Z Zhang, W. E. Minke, Z. Hou, C. L. M. J. Verlinde, W. G. J. Hol, J. Am. Chem. Soc. 2000, 122, 2663-2664; c) A. V. Pukin, H. M. Branderhorst, C. Sisu, C. Weijers, M Gilbert, R. M. J. Liskamp, G. M. Visser, H. Zuilhof, R. J. Pieters, ChemBioChem 2007, 8, 1500-1503.

[11] a) J. L. De Paz, P. H. Seeberger, QSAR Comb. Sci. 2006, 25, 1027-1032; b) I. Shin, S. Park, M. R. Lee, Chem. Eur. J. 2005, 11, 2894-2901; c) J. C. Paulson, O. Blixt, B. E. Collins, Nat. Chem. Biol. 2006, 2, 238-248; d) D. Wang, Proteomics 2003, 3, 2167-2175; e) T. Feizi, F. Fazio, W. Chai, C.-H. Wong, Curr. Opin. Struct. Biol. 2003, 13,637-645; f) S. Park, M. R. Lee, I. Shin, Chem. Soc. Rev. 2008, 37, 1579-1591; g) T. Horlacher, P. H. Seeberger, Chem. Soc. Rev. 2008, 37, 1414-1422; i) S. Park, M. R. Lee, Shin Chem. Commun. 2008, 4389-4399; j) N. Laurent, J. Voglmeir, S. L. Flitsch, Chem. Commun. 2008, 4400-4412; k) N. L. Pohl, Angew. Chem 2008, 120, 3930-3932; Angew. Chem. Int. Ed. 2008, 47, 3868-3870 I) C. Y. Wu, P. H. Liang, C. H. Wong, Org. Biomol. Chem. 2009, 7, 22472254; m) A. S. Culf, M. Cuperlovic-Culf, R. J. Ouellette, Omics 2006, 10, 289-310.

[12] a) K. T. Pilobello, L. Krishnamoorthy, D. Slawek, L. K. Mahal, ChemBioChem 2005, 6, 985-989; b) J. C. Manimala, T. A. Roach, Z. Li, J. C. Gildersleeve, Angew. Chem. 2006, 118, 3689-3692; Angew. Chem. Int. Ed. 2006, 45, 3607-3610; c) K. S. Ko, F. A. Jaipuri, N. L. Pohl, J. Am. Chem. Soc. 2005, 127, 13162-13163; d) B. T. Houseman, M. Mrksich, Chem. Biol. 2002, 9, 443-454; e) Z. Pei, H. Yu, M. Theurer, A. Waldén, P. Nilsson, M. Yan, O. Ramström, ChemBioChem 2007, 8, 166-168; f) J. L. de Paz, C. Noti, P. H. Seeberger, J. Am. Chem. Soc. 2006, 128, 2766-2767; g) E. W. Adams, D. M. Ratner, H. R. Bokesch, J. B. McMahon, B. R. O'Keefe, P. H. Seeberger, Chem. Biol. 2004, 11, 875-881; h) X.-L Sun, C. L. Stabler, C. S Cazalis, E. L. Chaikof, Bioconjugate Chem. 2006, 17, 52-57; i) S. Park M. R. Lee, I. Shin, Bioconjugate Chem. 2009, 20, 155-162; j) L. Ban, M. Mrksich, Angew. Chem. 2008, 120, 3444-3447; Angew. Chem. Int. Ed. 2008, 47, 3396-3399; k) O. Blixt, K. Allin, O. Bohorov, X. F. Liu, H. Andersson-Sand, J. Hoffmann, N. Razi, Glycoconjugate J. 2008, 25, 59-68; I) F. A. Jaipuri, B. Y. M. Collet, N. L. Pohl, Angew. Chem. 2008, 120, 1731 1734; Angew. Chem. Int. Ed. 2008, 47, 1707-1710; m) A. R. de Boer, C. H. Hokke, A. M. Deelder, M. Wuhrer, Anal. Chem. 2007, 79, 8107-8113; n) Y. Chevolot, C. Bouillon, S. Vidal, F. Morvan, A. Meyer, J. P. Cloarec, A. Jochum, J. P. Praly, J. J. Vasseur, E. Souteyrand, Angew. Chem. 2007, 119, 2450-2454; Angew. Chem. Int. Ed. 2007, 46, 2398-2402; o) E. Cló, O. Blixt, K. J. Jensen, Eur. J. Org. Chem. 2010, 540-554.

[13] H. M. Branderhorst, R. Ruijtenbeek, R. M. J. Liskamp, R. J. Pieters, ChemBioChem 2008, 9, 1836- 1844.

[14] a) S. E. Jones, S. A. Ditner, C. Freeman, C. J. Whitaker, M. Lock, Appl. Environ. Microbiol. 1989, 55, 529-530; b) R. van Beuningen, H. Van Damme, P. Boender, N. Bastiaensen, A. Chan, T. Kievits, Clin. Chem. 2001, 47,
1931 -1933; c) Y. Wu, P. de Kievit, L. Vahlkamp, D. Pijnenburg, M. Smit, M. Dankers, D. Melchers, M. Stax, P. J. Boender, C. Ingham, N. Bastiaensen, R. de Wijn, D. van Alewijk, H. van Damme, A. K. Raap, A. B. Chan, R. van Beuningen, Nucleic Acids Res. 2004, 32, e123; Dankers, D. Melchers, M. Stax, P. J. Boender, C. Ingham, N. Bastiaensen, R. de Wijn, D. van Alewijk, H. van Damme, A. K. Raap, A. B. Chan, R. van Beuningen, Nucleic Acids Res. 2004, 32, e123; d) S. Lemeer, C. Jopling, F. Naji, R. Ruijtenbeek, M. Slijper, A.J.R. Heck, J. den Hartog, PloS ONE 2007, e581; e) S. Lemeer, R. Ruijtenbeek, M. W. H. Pinkse, C. Jopling, A. J. R. Heck, J. den Hertog, M. Slijper, Mol. Cell. Proteomics 2007, 2088-2099; f) A. J. Poot, J. van Ameijde, M. Slijper, A. van den Berg, R. Hilhorst, R. Ruijtenbeek, D. T. S. Rijkers, R. M. J. Liskamp, ChemBioChem 2009, 10, 2042-2051; g) R. Hilhorst, L. Houkes, A. van den Berg, R. Ruijtenbeek, Anal. Biochem. 2009, 387, 150-161.

[15] a) V. I. Dyukova, N. V. Shilova, O. E. Galanina, A. Y. Rubina, N. V. Bovin, Biochim. Biophys. Acta Gen. Subj. 2006, 1760, 603-609; b) X. Zhou, C. Turchi, D. Wang, J. Proteome Res. 2009, 8, 5031-5040; c) T. Fukuda, S. Onogi, Y. Miura, Thin Solid Films 2009, 518, 880-888.

[16] J. A. F. Joosten, N. T. H. Tholen, F. Ait El Maate, A. J. Brouwer, G. W. van Esse, D. T. S. Rijkers, R. M. J. Liskamp, R. J. Pieters, Eur. J. Org. Chem. 2005, 3182-3185.

[17] Structure with PDB ID: 2UVO, WGA (isolectin 1) bound to $\mathrm{N}$-acetylglucosamine. D. Schwefel, V. Wittmann, K. Diederichs, W. Welte, unpublished results. For recent WGA structures bound to multivalent ligands showing chelation see ref. [18]. Distances between the anomeric oxygens of the terminal nonreducing sugar of two bound carbohydrate ligands.

[18] D. Schwefel, C. Maierhofer, J. G. Beck, S. Seeberger, K. Diederichs, H. M. Möller, W. Welte, V. Wittmann, J. Am Chem. Soc. 2010, 132, 8704-8719.

[19] C. Maierhofer, K. Rohmer, V. Wittmann, Bioorg. Med. Chem. 2007, 15, $7661-7676$.

[20] R. Masaka, M. Ogata, Y. Misawa, M. Yano, C. Hashimoto, T. Murata, H. Kawagishi, T. Usui, Bioorg. Med. Chem. 2010, 18, 621-629.

[21] C. Sisu, A. J. Baron, H. M. Branderhorst, S. D. Connel, C. Weijers, R. de Vries, E. D. Hayes, A. W. Pukin, M. Gilbert, R. J. Pieters, H. Zuilhof, G. M. Visser, W. B. Turnbull, ChemBioChem 2009, 10, 329-337.

[22] I. J. Goldstein, C.E. Hollerman, E. E. Smith, Biochemistry 1965, 4, 876883.

[23] a) L. A. Murphy, I. J. Goldstein, J. Biol. Chem. 1977, 252, 4739-4742; b) J. Lescar, J. F. Sanchez, A. Audfray, J. L. Coll, C. Breton, E. P. Mitchell, A. Imberty, Glycobiology 2007, 17, 1077-1083; c) W. Tempel, S. Tschampel, R. J. Woods, J. Biol. Chem. 2002, 277, 6615-6621.

[24] a) E. Fan, E. A. Merritt, C. L. M. J. Verlinde, W. G. J. Hol, Curr. Opin. Struct. Biol. 2000, 10, 680-686; Structure with PDB ID: 3CHB, cholera toxin Bpentamer bound to the GM1 oligosaccharide, see: b) E. A. Merritt, P. Kuhn, S. Sarfaty, J. L. Erbe, R. K. Holmes, W. G. J. Hol, J. Mol. Biol. 1998, 282, 1043-1059.

[25] a) J. F. Crowley, I. J. Goldstein, FEBS Lett. 1981, 130, 149-152; b) J. F. Crowley, I. J. Goldstein, J. Arnarp, J. Lönngren, Arch. Biochem. Biophys. $1984,231,524-533$

[26] a) I. K. Howard, H. J. Sage, M. D. Stein, N. M. Young, N. M. Leon, D. F. Dyckers, J. Biol. Chem. 1971, 246, 1590-1595; b) R. Loris, J. Steyaert, D. Maes, J. Lisgarten, R. Pickersgill, L. Wyns, Biochemistry 1993, 32, 8772 8781 ; c) F. Casset, T. Hamelryck, R. Loris, J. R. Brisson, C. Tellier, M. H. Daothi, L. Wyns, F. Poortmans, S. Perez, A. Imberty, J. Biol. Chem. 1995, $270,25619-25628$.

[27] A. Imberty, M. Wimmerova, E. P. Mitchell, N. Gilboa-Garber, Microbes Infect. 2004, 6, 221-228.

[28] a) H. Einspahr, E. H. Parks, K. Suguna, E. Subramanian, F. L. Suddath, J. Biol. Chem. 1986, 261, 16518-16527; b) S. N. Ruzheinikov, I. Y. Mikhailova, I. N. Tsygannik, W. Pangborn, W. Duax, V. Z. Pletnev, Russ. J. Bioorg. Chem. 1998, 24, 277-279.

[29] a) J. London, S. Berrih, J.-F. Bach, J. Immunol. 1978, 121, 438-443; b) S. Kundhavai Natchiar, K. Suguna, A. Surolia, M. Vijayan, Crystallogr. Rev. 2007, 13, 3-28; c) R. Ravishankar, K. Suguna, A. Surolia, M. Vijayan, Acta Crystallogr. Sect. D: Biol. Crystallogr. 1999, 55, 1375-1382.

[30] P. N. Kanellopoulos, K. Pavlou, A. Perrakis, B. Agianian, C. E. Vorgias, C. Mavrommatis, M. Soufi, P. A. Tucker, S. J. Hamodrakas, J. Struct. Biol. $1996,116,345-355$.

[31] a) J. J. Garcia-Lopez, F. Hernandez-Mateo, J. Isac-Garcia, J. M. Kim, R. Roy, F. Santoyo-Gonzalez, A. Vargas-Berenguel, J. Org. Chem. 1999, 64, 522- 
531; b) M. Chwalek, R. Auzely, S. Fort, Org. Biomol. Chem. 2009, 7 $1680-1688$.

[32] O. Srinivas, N. Mitra, A. Surolia, N. Jayaraman, Glycobiol. 2005, 15, 861 873.

[33] W. B. Turnbull, B. L. Precious, S. W. Homans, J. Am. Chem. Soc. 2004, 126, 1047-1054.

[34] a) D. Arosio, I. Vrasidas, P. Valentini, R. M. J. Liskamp, R. J. Pieters, A. Bernardi, Org. Biomol. Chem. 2004, 2, 2113-2124; b) H. M. Branderhorst, R. M. J. Liskamp, G. M. Visser, R. J. Pieters, Chem. Commun. 2007, 50435045.

[35] Z. Zhang, J. C. Pickens, W. G. J. Hol, E. Fan, Org. Lett. 2004, 6, $1377-$ 1380 .

[36] G. Cioci, E. P. Mitchell, C. Gautier, M. Wimmerova, D. Sudakevitz, S. Perez, N. Gilboa-Garber, A. Imberty, FEBS Lett. 2003, 555, 297-301.

[37] B. Lanne, J. Ciopraga, J. Bergstrom, C. Motas, K. A. Karlsson, Glycoconjugate J. 1994, 11, 292-298.
[38] L. Moni, G. Pourceau, J. Zhang, A. Meyer, S. Vidal, E. Souteyrand, A. Dondoni, F. Morvan, Y. Chevolot, J. J. Vasseur, A. Marra, ChemBioChem 2009, 10, $1369-1378$.

[39] C. Chemani, A. Imberty, S. de Bentzmann, M. Pierre, M. Wimmerova, B. P. Guery, K. Faure, Infect. Immun. 2009, 77, 2065-2075.

[40] a) Z. Dai, J. Zhou, S. J. Qiu, Y. K. Liu, J. Fan, Electrophoresis 2009, 30 2957-2966; b) J. Hirabayashi, J. Biochem. 2008, 144, 139-147.

[41] a) M. Gómez-Garcia, J. M. Benito, D. Rodríguez-Lucena, J.-X Yu, K Chmurski, C. Ortiz Mellet, R. Gutiérrez Gallego, A. Maestre, J. Defaye, J. M. García Fernández, J. Am. Chem. Soc. 2005, 127, 7970-7971; b) V. Duléry, O. Renaudet, M. Wilczewski, A. Van der Heyden, P. Labbé, P. Dumy, J. Comb. Chem. 2008, 10, 368-371.

[42] J. W. Goding, J. Immunol. Methods 1976, 13, 215-226. 